\title{
DESIGNING AND TESTING THE REPRESENTATIVE SAMPLERS FOR SAMPLING A MILLING CIRCUIT AT NKANA COPPER/COBALT CONCENTRATOR
}

\author{
Chibwe, P. ${ }^{1}$, Simukanga, S. ${ }^{1}$, Witika, L.K. ${ }^{1}$, Chisanga, P. ${ }^{2}$ and Powell, M. ${ }^{3}$ \\ ${ }^{1}$ University of Zambia, School of Mines, Department of Metallurgy and Mineral Processing, \\ P. O. Box 32379, Lusaka Zambia \\ ${ }^{2}$ Nkana Division, Concentrator, Zambia Consolidated Copper Mines \\ ${ }^{3}$ University of Capetown, Department of Mechanical Engineering, Private Bag, \\ Rondebosch 7700, South Africa
}

\begin{abstract}
The primary objective in any ore processing method, is to prepare the ore for economical and effective extraction the valuable minerals. Milling circuits are extremely energy intensive, making them very expensive operations and it is very pertinent to optimise their operation to be economically viable. Therefore, their design is very critical and this can only be achieve by adopting new control strategies to improve energy utilisation. Nkana Mine concentrator of the Zambia Consolidated Copper Mines Limited (ZCCM) has been experiencing problems in establishing the optimum mesh of grind for the various ores, to achieve effective separation of the cobalt minerals from those of copper. This prompted the designing and testing of representative samplers for sampling the milling circuit at Nkana Concentrator. In the design of the samplers, use was made of the Gy's formula to determine the minimum weight of the sample to be extracted from various process streams. The particle size distribution of the streams was conducted to determine the size of the largest particle in each stream. Samplers were designed on the basis of theoretical and practical applications and a factor of three was built in the normal sampler width opening. This enabled that the entire stream had equal chance of entering the sampler.The milling circuit on which a sampling campaign was conducted consisted of a $2.7 \mathrm{~m}$ by $3.6 \mathrm{~m}$ (9ft, 12ft) Rod Mill in open circuit with a $760 \mathrm{~mm}$ (30inch) hydrocyclone which was in closed circuit with a Ball Mill of the same dimension as the Rod Mill. Samples were taken from the feed to the Rod Mill, Rod Mill discharge, Cyclone underflow (feed to the Ball Mill), Ball Mill discharge and the cyclone overflow using appropriate sampling techniques for a complete shift at equally spaced intervals. Sampling was only started when it was established that steady state operation of the plant was attained. Important operating parameters were established which included the throughput of the material to the Rod Mill, the pulp densities of the streams in the milling circuit, the particle size distribution of the streams, volumetric flow rates of the streams and the rate at which dilution water was added. These parameters were then used to carry out Mass balancing using a mineral processing simulation software called JKSimMet which has been developed by the Julius Kruttschnitt Mineral Research Centre at the University of Queensland in Australia. The simulator can be used to predict the possible alternatives to optimising the circuit performance and physical modifications which can be made to the plant with confidence. The correlation between the measured and the calculated parameters was found to be fairly satisfactorily. This showed that the designed samplers and the sampling techniques used were suitable for obtaining representative samples from the milling circuit. This paper describes the method used in designing the samplers, the sampling techniques used and the results obtained from the JKSimMet software.
\end{abstract}

KEYWORDS: Sampling, grinding, mass balancing, JKSimMet simulator. 


\section{INTRODUCTION}

In order to obtain useful information on the efficiency of crushing and milling operations, routine sampling of the various streams of crushing and milling circuits is an important exercise to optimise use of energy. Sampling is the removal of an appropriate amount of a material from the bulk for testing to get information on the various properties of the bulk material. The samples should be drawn in such a way that the proportion and distribution of the quantity to be tested is the same, in both the lot and the sample. It is, therefore, desired that appropriate samplers and sampling techniques are used for different process streams.

It is important that any sample must be representative of the lot. It is therefore necessary to establish the relationship between the minimum weight of the sample required and the maximum particle size of the sample, so as to ensure that any sample taken is representative of the lot.

Since most of the decisions made on a metallurgical plant, such as process flowsheet developments, methods of improving recoveries and grades and reducing losses etc are based on the results obtained from sampling, it is imperative that the reliability of the samples and the methods used in obtaining them are carefully controlled and quantified.

\section{SAMPLINGTHEORY}

Sampling is a statistical technique based on the theory of probability. It should minimise the errors arising from various variables, such as surging, segregation of the sizes in ore bins, etc ${ }^{1}$.

Gy's formula may be used to determine the minimum weight of the sample that is as representative as the lot. In it's simplest form, it is given as ${ }^{3}$ :

$\sigma^{2}=\left(\frac{1}{M_{S}}-\frac{1}{M_{L}}\right) m f g l d^{3}$

$\sigma^{2}$ is the relative variance of the fundamental error.

$\mathrm{M}_{\mathrm{S}}$ is the mass of the sample in grams that is supposed to be drawn from the Lot.

$M_{L}$ is the mass of the Lot from which the sample is drawn, measured in grams. $\mathrm{m}$ is the mineralogical composition factor and is given as;

$m=\left(\frac{1-a}{a}\right)\left[(1-a) \rho_{m}-a \rho_{g}\right]$

where:

$\mathrm{a}$ is the decimal proportion of the mineral.

$\rho_{m}$ is the specific gravity of the valuable mineral.

$\rho_{g}$ is the specific gravity of the gangue mineral.

If the portion of the mineral is less than 0.05 , it is sufficient to take

$m=\left(\frac{1-a}{a}\right)^{2} \rho_{m}$

$\mathrm{f} \quad$ is the shape factor. It is taken as an index varying from zero to one and in practice, it has values between 0.2 and 0.5 . For most ores, $\mathrm{f}$ is a constant and equal to 0.5 . If the mineral particles are flat, flaky or elongated, $\mathrm{f}$ is set equal to 0.2 and is a dimensionless factor.

$\mathrm{g}$ is the size range factor. This is the ratio of the sieve aperture $(\mathrm{d})$ which retains $5 \%$ oversize material, to the sieve aperture which passes 5\% undersize material (d'). $g$ is usually taken to be 0.25 and is also a dimensionless factor.

1 is the liberation factor. It varies from zero (all particles have the same mineral content and are perfectly homogeneous) to unit (total liberation - particles are either mineral or gangue). Intermediate values of 1 are given in table 1 below $^{4}$ :

Table1: Liberation factor (1) as a function of particle size (d)

\begin{tabular}{|l|l|c|c|c|c|c|c|}
\hline Liberation factor 1 & 1 & 0.8 & 0.4 & 0.2 & 0.1 & 0.05 & 0.02 \\
\hline $\mathrm{d} / \mathrm{d}_{\mathrm{O}}$ & 1 & $1-4$ & $4-10$ & $10-40$ & $40-100$ & $100-400$ & 400 \\
\hline
\end{tabular}

$\mathrm{d}_{\mathrm{O}}$ is the particle size at which complete liberation occurs

1 can also easily be obtained by using the formula;

$l=\sqrt{\frac{d_{o}}{d}}$

$\mathrm{d}$ is the maximum particle size in the Lot to be sampled. In practice it is taken as the size of the sieve aperture which retains $5 \%$ oversize material, and is measured in centimetres. 


\section{EXPERIMENTALPROCEDURE}

A survey was conducted on the Nkana concentrator Copper/Cobalt milling circuit, shown below in figure 1, in order to come up with the suitable shapes of the samplers to be designed and, the appropriate techniques to be used in extracting the representative samples from the various milling circuit streams.

Before sampling process could be started, it was ensured that the milling circuit was stabilised by allowing it run for a period of atleast three hours in which, the solids feedrate to the primary mill (Rod mill), read on the bench meter, and the surface level of the bath in the sump box were constantly observed. The pulp densities of the streams were also measured at an interval of 15 minutes within the same period. When it was ensured that the circuit became as close as possible to steady state operation, sampling exercise was then ready to be conducted.

\section{Sampling Technique.}

When drawing the samples from the process streams, the sampler was moved completely across the stream at a uniform speed. The selected sampling point was that point for each stream at which the material in the stream was falling freely, preferably vertically. The cutter was moved perpendicular to the freely falling stream, sampling the entire stream for the same length of time. It was passed well clear of the falling stream before it could begin the return stroke to avoid stray particles falling into it, whilst ensuring that the samplers did not overflow.

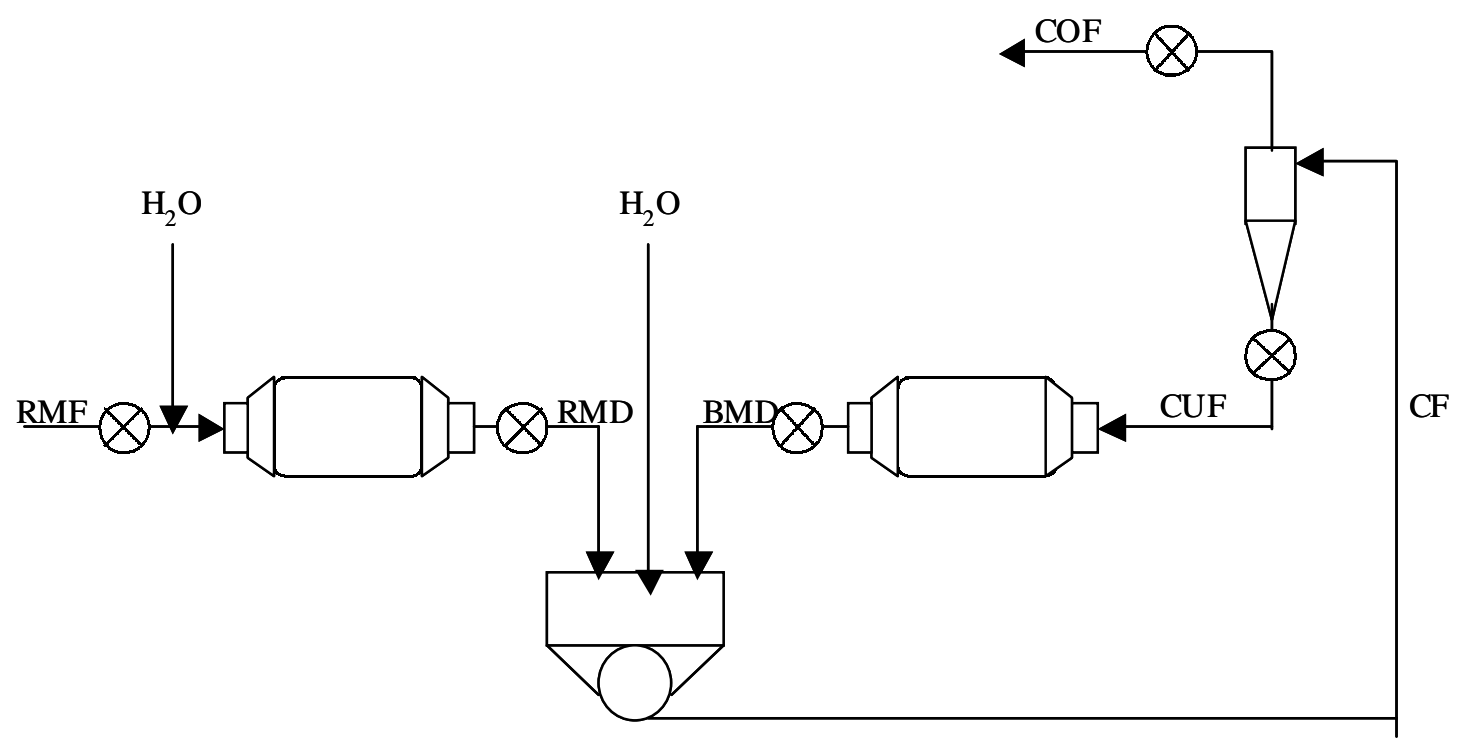

$\begin{array}{lllll}\otimes & - & \text { Sampling points } & \text { CF } & - \text { Hydrocyclone Feed } \\ \text { RMF } & - & \text { Rod Mill Feed } & \text { CUF } & - \text { Hydrocyclone Underflow } \\ \mathrm{H}_{2} \mathrm{O} & - & \text { Water RMF } & \text { COF } & - \text { Hydrocyclone Overflow } \\ \text { RMD } & - & \text { Rod Mill Discharge } & \text { BMD } & - \text { Ball Mill Discharge }\end{array}$

Figure 1: Nkana Concentrator Milling circuit 
Once successfully taken, the sample was poured in a smooth motion into a clean bucket immediately after sampling in order to minimise the settling out of particles in the sampler. The material left in the cutter after decanting was scraped out into the bucket. To minimise the error introduced by the film of particles inevitably left on the surface of the sampler, the sampler was rinsed under the stream and shaken out directly prior to taking the sample. This was done to ensure that the sampler maintained similar coating prior to and after sampling.

\section{Composite Sample}

During the sampling exercise, samples were drawn from RMD, CUF, COF and BMD at an interval of 10 minutes over a period of one hour. The 6 samples obtained from each stream during the sampling test were poured into the same clean labelled sample bucket to form composite samples. The buckets were then covered with tight lids to avoid evaporation.

\section{Ore Feedrate}

The ore feedrate to the primary mill was kept constant through out the testwork. The speed of the belt was measured by timing a marked point over a fixed belt length $(10.84 \mathrm{~m})$ for 6 times and the average was taken.

Directly after the sampling of the streams, the belt feeding the material to the primary mill was stopped and a sample was cut over a fixed length of 1 meter from the belt. This was the only length of the belt which was accessible. The feed sample weight was measured and recorded immediately after collection, then dried and reweighed. The difference in weights was taken as the weight of the moisture in fresh feed.

By carrying out a belt cut, the solids feedrate and the water content in the fresh feed to the primary mill were determined to be used later in the JKSimMet software to carry out a mass of the entire circuit.

\section{Water Addition}

Water was first introduced into the Primary mill together with the fresh feed from the Storage bins and in the sump box at the discharge point to dilute the pulp.

The flow of water was measured using the flowmeter. The bucket and stopwatch method was tried, but due to high flowrates, it could not work.

Once the stabilised flowrates of water were measured, the valve openings were left untouched.

\section{Sample preparation}

The total individual composite samples were weighed wet while still in the collection bucket, then pressure filtered, using tarred filter paper before being placed on a pan and oven for drying over night at a temperature of about $55^{\circ} \mathrm{C}$. The dried samples were then re-weighed and the percent solids calculated. Care was taken to ensure that no portion of the dried samples were lost as this could have resulted in obtaining wrong values for percent solids.

\section{Particle size distribution of samples}

Particle size distribution of the samples was done using a comprehensive set of screens right down to $38 \mu \mathrm{m}$. The samples were prepared in a consistent manner, and all screening done under standard and unvarying conditions to ensure self-consistency and reproducibility of the results.

The dried Rod Mill Feed Sample was screened starting with a $34600 \mu \mathrm{m}$ screen, while the other samples (i.e RMD, CUF, COF and BMD) were done with a $3350 \mu \mathrm{m}$ screen down to $1200 \mu \mathrm{m}$. The $1200 \mu \mathrm{m}$ undersize was homogenised and riffled to produce a sub-sample of about $250 \mathrm{~g}$ which was weighed and then wet screened on a $45 \mu \mathrm{m}$ screen. The undersize material of wet screening was collected, dried and stored temporarily in sample bags. The oversize material was dried, weighed and screened on a stack of sieves mounted on a rotap sieve shaker with a sieving time of 20 minutes. The minus $45 \mu \mathrm{m}$ material was combined with the one from wet screening and the total weight recorded.

\section{Designing of Sample Cutters}

In the designing of samplers( sample cutter), the largest particle size, slurry flowrate, the width of the stream and the time taken to cut the sample for each stream were considered.

Using the already designed samplers found on the plant, samples were drawn from the circuit streams at an interval of 10 minutes for a period of one hour. This constituted a set. The six samples from each stream were composited and then dried and their dry weights recorded. Five sets were collected. The results obtained from the sieve analysis of these samples were then used in the determination of the width of the opening .

The width of the sampler mouth was taken to be eight times the size of the largest particle in all the stream except for the hydrocyclone overflow in which it was taken to be 
thirty times so as to conform with the recommended minimum width of the sampler mouth of $9 \mathrm{~mm}$.

The length of the opening of the sampler mouth was obtained by measuring the cross section of each stream in the milling circuit. It was taken to be larger than the measured cross section of each stream so that the stream can be accommodated sufficiently without any part of it to remain unsampled. The calculated volume of the sampler was made sufficiently to hold the full sample without any overflow occurring. It was computed to be $50 \%$ greater than that of the sample to be collected. The estimated volume of the sampler was obtained from the volumetric flow rate of the stream and an estimated sampling time made from the width of the stream and the open area of the sampler mouth. The formula used for computation of volume of the sampler is:

Vol. $=1.5 \times$ Stream flow $x\left(\frac{\text { Sample cutter gap }}{\text { full width of Stream }}\right) \times$ Time to cut sample

The designed samplers were attached to handles to allow easy access to the streams.

\section{Testing of Designed Samplers}

After the samplers were successfully designed, they were then tested for drawing representative samples from the milling circuit streams using appropriate sampling techniques, sample preparations and sizing procedure as explained above.

The main objective of testing was to see whether the designed samplers were capable of drawing representative samples that could conform with the calculated parameters( i.e weight of the sample and the volume of the sample in the sampler).

\section{RESULTS AND DISCUSSION}

Estimation of Sample Weight to be drawn from the bulk

\section{(a) Determination of $\mathbf{d}$ (maximum particle size in the stream)}

The results obtained by using the samplers found on the plant for the determination of the largest particle size for each stream in the circuit are presented in figure 2 .

The average values of $d$ as obtained from the graphs were as follows:

$\begin{array}{lll}\text { Rod Mill Discharge } & = & 2400 \mu \mathrm{m} \\ \text { Hydrocyclone Underflow } & = & 2000 \mu \mathrm{m} \\ \text { Hydrocyclone Overflow } & = & 300 \mu \mathrm{m} \\ \text { Ball Mill Discharge } & = & 1300 \mu \mathrm{m}\end{array}$

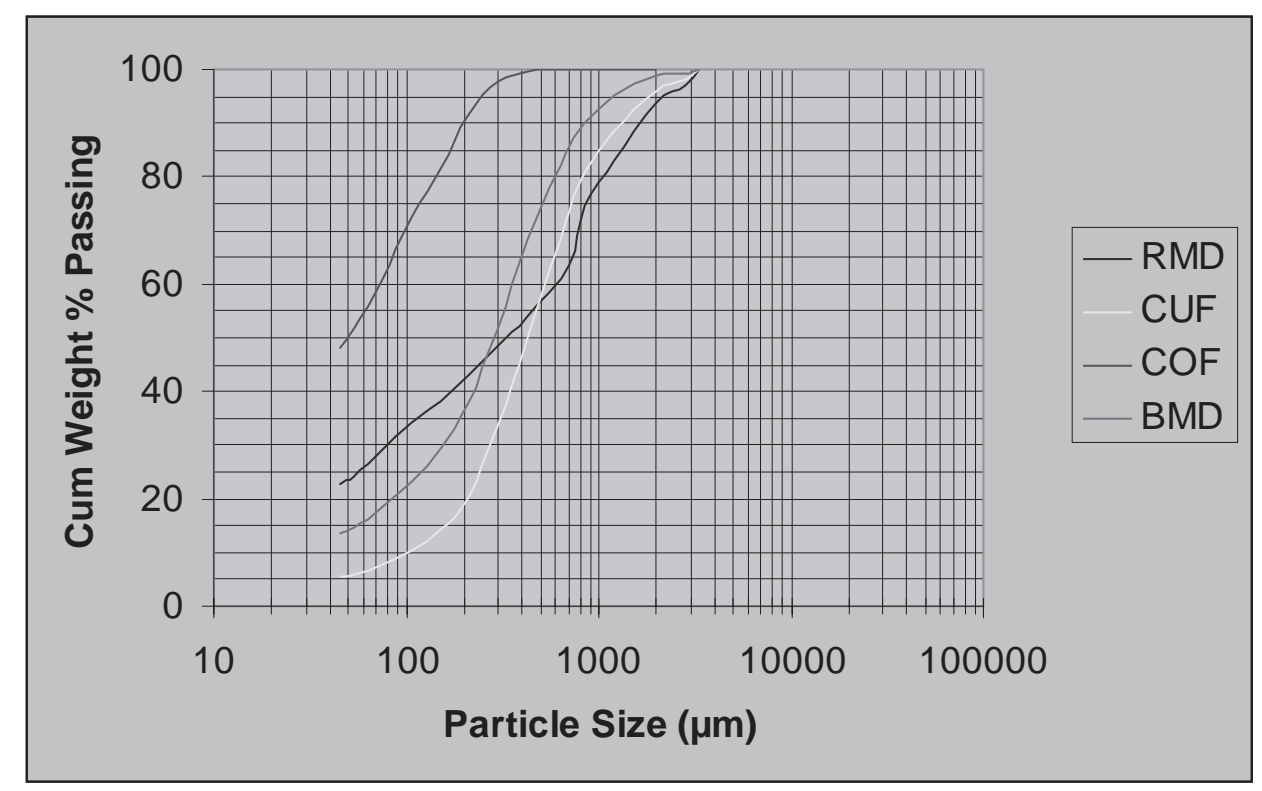

Figure 2: Cumulative Weight percent passing vs particle size for various streams 


\section{(b) Determination of $\mathrm{m}$}

The mineralogical data for Nkana mine Concentrator Composite copper/cobalt ore at the time of the testwork was as given below in Table 1 , below.

Table 1: Mineralogical Data For Nkana Primary Mill Feed

\begin{tabular}{|l|c|c|c|}
\hline Ore Mineral & Weight $\%$ & $\%$ TcU & $\%$ Tco \\
\hline Chalcopyrite & 3.49 & 1.2 & - \\
\hline Bornite & 0.44 & 0.28 & - \\
\hline Chalcocite & 0.03 & 0.02 & - \\
\hline Pyrite & 1.46 & - & $?$ \\
\hline Carrollite & 0.2 & 0.04 & 0.04 \\
\hline Pyrrhotite & 0.03 & - & - \\
\hline Native Copper & 0.01 & 0.01 & - \\
\hline Gangue & 94.34 & - & - \\
\hline Total & 100 & 1.55 & 0.04 \\
\hline
\end{tabular}

Mineralogical composition factor is given as:

$$
m=\left(\frac{1-a}{a}\right)\left[(1-a) \rho_{m}-a \rho_{g}\right]
$$

(i) value of ' $m$ ' when considering copper.

Equivalent Mineral.

$$
\begin{array}{ll}
3.43 \times \mathrm{CuFeS}_{2} & =\mathrm{Cu}_{3.49} \mathrm{Fe}_{3.49} \mathrm{~S}_{6.98} \\
0.44 \times \mathrm{xu}_{5} \mathrm{FeS}_{4} & =\mathrm{Cu}_{2.2} \mathrm{Fe}_{0.44} \mathrm{~S}_{1.76} \\
0.03 \times \mathrm{Cu}_{2} \mathrm{~S} & =\mathrm{Cu}_{0.06} \mathrm{~S}_{0.03} \\
0.20 \times \mathrm{CuCo}_{2} \mathrm{~S}_{4} & =\mathrm{Cu}_{0.2} \mathrm{Co}_{0.4} \mathrm{~S}_{0.8} \\
\underline{0.01 \times C u} & =\underline{\mathrm{Cu}_{0.01}}
\end{array}
$$

$\therefore$ Equivalent Mineral $=\mathrm{Cu}_{5.96} \mathrm{Fe}_{3.93} \mathrm{Co}_{0.4} \mathrm{~S}_{9.57}$

Decimal Portion of the equivalent Mineral is: $\frac{[(0.0349+0.0044+0.003+0.002+0.0001)(5.96 \times 63.55+3.93 \times 55.85+9.57 \times 32.06+0.4 x 58.93)]}{(5.96 \times 63.55)}=a$

$$
a=(0.0417 \times 928.67298) /(378.759)=0.102
$$

The solids Specific( S.G) of the equivalent Mineral is:

$$
\begin{aligned}
\rho_{m}= & \{(\% A+\% B+\ldots \ldots . \% N)\} \\
& \{[\% A / S . G(A)]+[\% B / S . G(B)]+\ldots \ldots . .[\% N S . G(N)]\}
\end{aligned}
$$

where $\mathrm{N}$ is the total number of Minerals containing the value of interest (copper in this case).

$$
\begin{aligned}
& \rho_{m}=\frac{[3.49+0.44+0.03+0.2+0.01]}{[(3.49 / 4.2)+(0.44 / 5.15)+(0.03 / 5.65)+(0.2 / 4.9)+(0.01 / 8.9)]} \\
& \rho_{m}=(4.17 / 0.9636)=4.33 \mathrm{~g} / \mathrm{cm}^{3}
\end{aligned}
$$

The specific gravity of the gangue material is:

$[(4.17 / 100) x 4.33]+\left[(95.83 / 100) x \rho_{g}=\right.$ Ore specific gravity

but the Specific Gravity for the Feed to the Primary Mill was determined to be $2.70 \mathrm{~g} / \mathrm{cm}^{3}$,

therefore,

$[(4.17 / 100) x 4.33]+\left[(95.83 / 100) x \rho_{g}=270\right.$

$$
\rho_{g}=2.63 \mathrm{~g} / \mathrm{cm}^{3}
$$

therefore, substituting in $\mathrm{m}$ we have

$$
\begin{aligned}
\mathrm{m} & =[(1-0.102) /(0.102)] \mathrm{x}[(1-0.102) \times 4.33+0.102 \times 2.63] \\
& =8.804(3.89+0.268) \\
& =36.609 \mathrm{~g} / \mathrm{cm}^{3}
\end{aligned}
$$

$$
\frac{[(0.0349+0.0044+0.003+0.002+0.0001)(5.96 \times 63.55+3.93 \times 55.85+9.57 \times 32.06+0.4 \times 58.93)]}{(5.96 \times 63.55)}=a
$$


(ii) value of ' $m$ ' when considering cobalt.

$\mathrm{CuCo}_{2} \mathrm{~S}_{4}=0.2 \%$

S.G of $\mathrm{CuCo}_{2} \mathrm{~S}_{4},\left(\rho_{\mathrm{m}}\right)=4.9 \mathrm{~g} / \mathrm{cm}^{3}$

$\mathrm{a}=(0.2 / 100)=0.002$

S.G of gangue mineral

$\Rightarrow(4.9 / 100) \times 0.2+\left(\rho_{\mathrm{g}} / 100\right) \times 98.8=2.7$

$\rho_{g}=2.723 \mathrm{~g} / \mathrm{cm}^{3}$

$m=[(1-0.002) / 0.002] x[(1-0.002) \times 4.9+0.002 \times 2.723]$

$=2442.9 \mathrm{~g} / \mathrm{cm}^{3}$

(c) Determination of 1

(i) value of 1 when considering copper.

$l=\sqrt{\frac{d_{o}}{d}}$ or from the table above under sampling theory.

$\mathrm{d}_{\mathrm{O}}=100 \mu \mathrm{m}$ (obtained from mineralogy Department)

therefore, putting $\mathrm{d}_{\mathrm{O}}$ and $\mathrm{d}$ (already determined above) we have 1 for

(1) Rod Mill Discharge $\quad=0.20$

(2) Hydrocyclone Underflow $=0.22$

(3) Hydrocyclone Overflow $=0.57$

(4) Ball Mill Discharge $\quad=0.27$

(ii) value of 1 when considering cobalt is the same for each stream as in Copper.

\section{(d) Other factors}

$\mathrm{f}$ and $\mathrm{g}$ are constants which are dimensionless as explained in the sampling theory above.

$\mathrm{f}=0.5$ and $\mathrm{g}=0.25$

\section{(e) Fundamental Variance}

$\sigma=\left(\frac{a^{\prime}}{2 a_{L}}\right)$

where $a^{\prime}$ is the tolerated error expressed as $\pm a^{\prime}$, and $\mathrm{a}_{\mathrm{L}}$ is the grade of the ore. $\mathrm{a}^{\prime}$ and $\mathrm{a}_{\mathrm{L}}$ are expressed in the same unit, irrespective of the unit given.

(i) value of $\sigma^{2}$ when considering copper $\mathrm{a}^{\prime}=0.01 \% \mathrm{Cu}$ (obtained from analytical services)

$\mathrm{a}_{\mathrm{L}}=1.55 \% \mathrm{Cu}$

$\therefore \sigma^{2}=[0.01 /(2 \times 1.55)]^{2}=1.04 \times 10^{-5}$

(ii) value of $\sigma^{2}$ when considering cobalt

$$
\begin{aligned}
& \mathrm{a}^{\prime}=0.1 \% \mathrm{Co} \\
& \mathrm{a}_{\mathrm{L}}=0.04 \% \mathrm{Co} \\
& \therefore \sigma^{2}=[0.1 /(2 \times 0.04)]^{2}=1.562
\end{aligned}
$$

\section{(f) Recommended minimum sample weight}

(i) when considering copper

$$
M_{s}=\left(\frac{1}{\sigma^{2}}\right) f g l m d^{3}
$$

(1) Rod Mill Discharge $\quad=96100 \times 0.5 \times 0.25 \times 0.2 \times 36.609 \times(0.24)^{3}=1337.5 \mathrm{~g}$ (2) Hydrocyclone Underflow $=96100 \times 0.5 \times 0.25 \times 0.22 \times 36.609 \times(0.2)^{3}=774.0 \mathrm{~g}$

(3) Hydrocyclone Overflow $=96100 \times 0.5 \times 0.25 \times 0.57 \times 36.609 \times(0.03)^{3}=6.8 \mathrm{~g}$

(4) Ball Mill Discharge $\quad=96100 \times 0.5 \times 0.25 \times 0.27 \times 36.609 \times(0.13)^{3}=260.9 \mathrm{~g}$

(ii) when considering cobalt

(1) Rod Mill Discharge $\quad=0.64 \times 0.5 \times 0.25 \times 0.20 \times 2442.9 \times(0.24)^{3}=0.54 \mathrm{~g}$ (2) Hydrocyclone Underflow $=0.64 \times 0.5 \times 0.25 \times 0.22 \times 2442.9 \times(0.2)^{3}=0.34 \mathrm{~g}$ (3) Hydrocyclone Overflow $=0.64 \times 0.5 \times 0.25 \times 0.57 \times 2442.9 \times(0.03)^{3}=0.003 \mathrm{~g}$ (4) Ball Mill Discharge $\quad=0.64 \times 0.5 \times 0.25 \times 0.27 \times 2442.9 \times(0.13)^{3}=0.12 \mathrm{~g}$

The minimum sample weights obtained when considering copper are larger than the ones obtained when considering cobalt. Therefore, the weights obtained when considering copper are recommended, because they are large enough to accommodate those for cobalt.

If the weight of a drawn sample is less than the calculated, then it may not be representative. And if it is too large compared to calculated one, it brings about difficulties in sample handling which introduces other sampling errors.

\section{DESIGNING OF SAMPLERS}

\section{(i) Computation of width of sampler mouth.}

Rod Mill Discharge

Hydrocyclone Underflow

Hydrocyclone Overflow

Ball Mill Discharge

$$
\begin{aligned}
& =2400 \mu \mathrm{m} \times 8=19200 \mu \mathrm{m} \\
& =2000 \mu \mathrm{m} \times 8=16000 \mu \mathrm{m} \\
& =300 \mu \mathrm{m} \times 30=9000 \mu \mathrm{m} \\
& =1300 \mu \mathrm{m} \times 8=10400 \mu \mathrm{m}
\end{aligned}
$$


(ii) Measured lengths of stream cross- sections

$\begin{array}{ll}\text { Rod Mill Discharge } & =10 \mathrm{~cm} \\ \text { Hydrocyclone Underflow } & =12 \mathrm{~cm} \\ \text { Hydrocyclone Overflow } & =10 \mathrm{~cm} \\ \text { Ball Mill Discharge } & =10 \mathrm{~cm}\end{array}$

\section{(iii) Estimation of Lengths of sampler mouths}

The estimation of the lengths of sampler mouths was done on the basis of the measured lengths of stream crosssections. They were taken to be larger than the measured stream cross-sections to ensure that the entire stream was well accommodated and that no part of the stream was left outside the sample cutter mouth when the sample was being drawn. The estimated values were:

$$
\begin{array}{ll}
\text { Rod Mill Discharge } & =26.0 \mathrm{~cm} \\
\text { Hydrocyclone Underflow } & =27.0 \mathrm{~cm} \\
\text { Hydrocyclone Overflow } & =28.0 \mathrm{~cm} \\
\text { Ball Mill Discharge } & =26.0 \mathrm{~cm}
\end{array}
$$

\section{(iv) Volume of samplers}

The time taken to cut the sample was approximated by using the already designed samplers. Stream flowrates were approximately determined from previous mass balances.

\footnotetext{
(1) Rod Mill Discharge $\Rightarrow$ time $=1.2$ seconds, stream flowrates $=46.29 \mathrm{~m}^{3} / \mathrm{h}$

(2) Hydrocyclone Underflow $\Rightarrow$ time $=0.9$ seconds, stream flowrates $=120.21 \mathrm{~m}^{3} / \mathrm{h}$

(3) Hydrocyclone Overflow $\Rightarrow$ time $=1.3$ seconds, stream flowrates $=185.09 \mathrm{~m}^{3} / \mathrm{h}$

(4) Ball Mill Discharge $\Rightarrow$ time $=1.0$ seconds, stream flowrates $=120.21 \mathrm{~m}^{3} / \mathrm{h}$
}

The volume of the samplers were determined using the following formula,

Vol $=1.5 \times$ streamflow $x\left(\frac{\text { sampler cutter gap }}{\text { full width of stream }}\right) \times$ time to cut sample

The factor 1.5 is used to take into consideration the $50 \%$ volume greater than that of the sample to avoid overflowing.

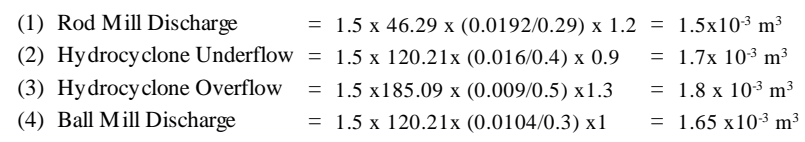

\section{(v) Dimensions of the samplers}

Figure 3 shows the sketch of the designed Rod Mill Discharge sampler. Similar shapes were constructed for CUF, COF and BMD with different dimensions as calculated above.

This shape of the sampler was chosen because the room left between the pulp discharging point and the walls of the sump box into which the stream was flowing was not large enough to provide the passage needed for cylindrical type of a cutter when drawing a sample for both the RMD and BMD sampling points. It was therefore adopted for all the streams.

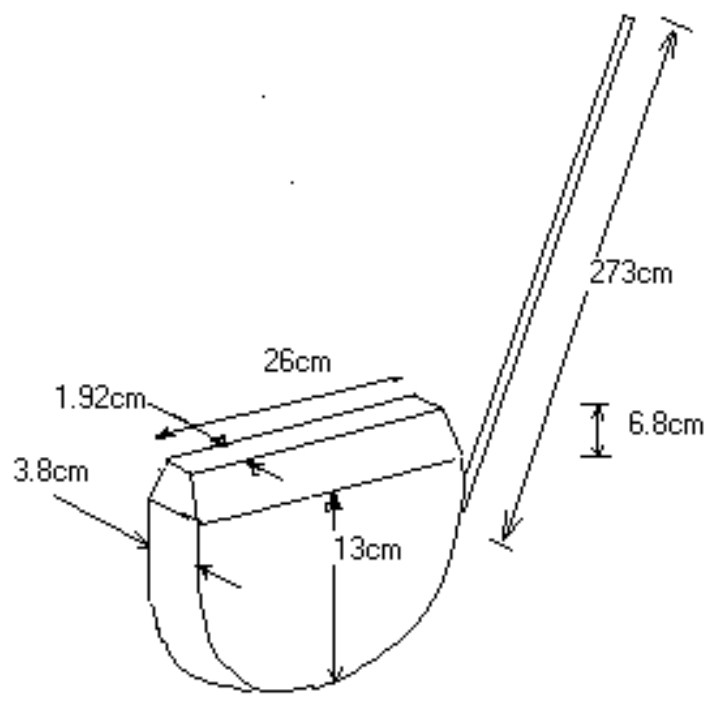

Figure 3: Designed Sampler for Rod Mill Discharge

\section{Testing the Designed Samplers}

After the samplers were successfully designed, they were then used to draw samples from which the parameters needed to carry out mass balance of the circuit using the JKSimMet Software were determined. 
(a) determination of solids feedrate to primary mill

Belt length considered for belt speed determination $=10.84$ meters

Average time taken for this belt length to pass $=21.58$ Seconds

Belt Speed $=10.84 \mathrm{~m} / 21.58 \mathrm{~s}=0.502 \mathrm{~m} / \mathrm{s}$

This speed was maintained throughout the test.

Wet Weight of the sample from belt cut (1 meter considered) $=49.80 \mathrm{~kg}$

$\therefore$ Throughput

$$
=0.04980 \mathrm{t} \times(0.502 \times 3600) \mathrm{m} / \mathrm{h} \times 1 / 1 \mathrm{~m}=90.0 \mathrm{tph}
$$

(b) percent solids

$\%$ Solids $=($ Dry Weight $/$ Wet Weight $) \times 100 \%$

(c) water additions measurements

Water content in Primary Feed $=(0.04980-0.04827) \mathrm{t} x$ $(0.502 \times 3600) \mathrm{m} / \mathrm{h}=2.7$
Water introduced together with fresh feed in the Primary Mill $=18.7 \mathrm{~m}^{3} / \mathrm{h}$

Dilution Water added to sump box $=114.8 \mathrm{~m}^{3} / \mathrm{h}$

Water content in Primary Mill Discharge $=18+2.7=20.7 \mathrm{tph}$ Water content in Hydrocyclone Overflow

$$
=114.8+18.7+2.7=136.2 \mathrm{tph}
$$

\section{Mass Balance}

The parameters obtained from this testwork were used in the JKSimMet software to carry a full mass balance of the circuit. Table 2 below shows a typical tabulation of experimental and balanced data as obtained from JKSimMet.

It is seen from the table that, the data obtained is fairly consistent which confirms the validity of the designed samplers.

The comparison of experimental and balanced data is illustrated in figure 4 and can be seen to be fairly satisfactory. Figure 5 shows a simplified balanced milling circuit.

\begin{tabular}{|c|c|c|c|c|c|c|c|c|c|c|c|c|c|}
\hline & & \multicolumn{2}{|c|}{ RMF } & \multicolumn{2}{|c|}{ RMD } & \multicolumn{2}{|c|}{ CF } & \multicolumn{2}{|c|}{ CUF } & \multicolumn{2}{|c|}{ COF } & \multicolumn{2}{|c|}{ BMD } \\
\hline \multicolumn{2}{|l|}{ ITEM } & EXP & BAL & EXP & BAL & EXP & BAL & EXP & BAL & EXP & BAL & EXP & BAL \\
\hline Solids & Tph & 90.0 & 89.18 & & 89.18 & & 373.60 & & 284.4 & 90.0 & 89.18 & & 284.4 \\
\hline Solids S.G & $\mathrm{T} / \mathrm{m}^{3}$ & 2.70 & & 2.70 & & 2.70 & & 2.70 & & 2.70 & & 2.70 & \\
\hline Water & Tph & 2.78 & 3.11 & & 20.63 & & 205.45 & & 70.66 & 136.0 & 134.7 & & 70.66 \\
\hline$\%$ Solids & $\%$ & 97.0 & 96.63 & \begin{tabular}{|l|}
81.27 \\
\end{tabular} & 81.22 & & 64.52 & 80.14 & 80.10 & 39.81 & 39.83 & 80.14 & 80.10 \\
\hline Pulp S.G & $\mathrm{T} / \mathrm{m}^{3}$ & 2.57 & 2.55 & & 2.05 & & 1.68 & & 2.02 & & 1.33 & & 2.02 \\
\hline V. Flowrate & $\mathrm{m}^{3} / \mathrm{h}$ & 36.12 & 36.14 & & 53.65 & & 343.82 & & 176.0 & & 167.7 & & 176.0 \\
\hline$\%$ Pas sing $0.075 \mathrm{~mm}$ & $\%$ & 10.31 & 10.31 & 30.45 & 31.44 & & 19.93 & 9.65 & 9.20 & 54.31 & 54.17 & 15.89 & 16.32 \\
\hline $80.0 \%$ passes & $\mathrm{Mm}$ & 21.51 & 21.50 & 1.22 & 1.20 & & 0.8113 & 0.948 & 0.968 & 0.199 & 0.201 & 0.742 & 0.729 \\
\hline \multicolumn{2}{|c|}{ Sizings (mm) } & \multicolumn{12}{|c|}{ Sizing Format: Cumulative \% Passing } \\
\hline Top size & 34.600 & 100.0 & 100.0 & & & & & & & & & & \\
\hline & 24.500 & 87.36 & 87.39 & & & & & & & & & & \\
\hline & 19.000 & 71.85 & 71.88 & & & & & & & & & & \\
\hline & 16.000 & 64.71 & 64.74 & & & & & & & & & & \\
\hline & 11.200 & 53.34 & 53.33 & & & & & & & & & & \\
\hline & 9.510 & 49.26 & 49.25 & & & & & & & & & & \\
\hline & 6.350 & 41.82 & 41.80 & & & & & & & & & & \\
\hline & 3.350 & 31.78 & 31.80 & 100.0 & 100.0 & 100.0 & 100.0 & 100.0 & 100.0 & & 100.0 & 100.0 & 100.0 \\
\hline & 2.830 & 29.67 & 29.68 & 96.46 & 96.56 & 100.0 & 98.58 & 98.22 & 98.15 & 100 & 99.98 & 99.14 & 99.21 \\
\hline & 2.000 & 26.90 & 26.91 & 91.70 & 91.92 & 100.0 & 96.64 & 95.81 & 95.61 & 99.98 & 99.92 & 97.92 & 98.12 \\
\hline & 1.200 & 23.19 & 23.20 & 79.46 & 79.9 & 100.0 & 89.63 & 87.02 & 86.49 & 99.83 & 99.66 & 92.15 & 92.68 \\
\hline & 0.850 & 21.17 & 21.18 & 70.36 & 70.94 & 100.0 & 81.23 & 76.34 & 75.59 & 99.46 & 99.23 & 83.71 & 84.45 \\
\hline & 0.710 & 20.28 & 20.29 & 66.77 & 67.33 & 100.0 & 76.33 & \begin{tabular}{|l|}
69.71 \\
\end{tabular} & 69.26 & 99.03 & 98.9 & 78.72 & 79.16 \\
\hline & 0.425 & 17.98 & 17.99 & 56.41 & 57.10 & 100.0 & 57.24 & 46.02 & 45.25 & 95.72 & 95.49 & 56.56 & 57.28 \\
\hline & 0.300 & 16.61 & 16.61 & 50.72 & 51.59 & 100.0 & 45.28 & 32.48 & 31.42 & 89.83 & 89.50 & 42.28 & 43.30 \\
\hline & 0.212 & 15.16 & 15.17 & 45.62 & 46.52 & 100.0 & 36.36 & 23.19 & 22.3 & 81.49 & 81.21 & 32.32 & 33.18 \\
\hline & 0.150 & 13.59 & 13.60 & 40.27 & 41.21 & 100.0 & 29.27 & \begin{tabular}{|l|}
16.60 \\
\end{tabular} & 15.82 & 72.43 & 72.18 & 24.77 & 25.53 \\
\hline & 0.106 & 12.09 & 12.09 & 35.64 & 36.62 & 100.0 & 24.37 & 12.60 & 11.95 & 64.22 & 64.01 & 19.90 & 20.53 \\
\hline & 0.075 & 10.31 & 10.31 & 30.45 & 31.44 & 100.0 & 19.93 & 9.65 & 9.20 & 54.31 & 54.17 & 15.89 & 16.32 \\
\hline & 0.053 & 8.61 & 8.61 & 25.37 & 26.44 & 100.0 & 16.54 & 7.77 & 7.30 & 46.14 & 45.99 & 12.98 & 13.43 \\
\hline & 0.045 & 7.93 & 7.94 & 23.40 & 24.51 & 100.0 & 15.25 & 7.09 & 6.74 & 42.50 & 42.39 & 12.01 & 12.34 \\
\hline & 0.000 & 0.00 & 0.00 & 0.00 & 0.00 & 0.00 & 0.00 & 0.00 & 0.00 & 0.00 & 0.00 & 0.00 & 0.00 \\
\hline
\end{tabular}

Table 2: Comparison of Experimental and Balanced data for Mill Unit No 7 Nkana 


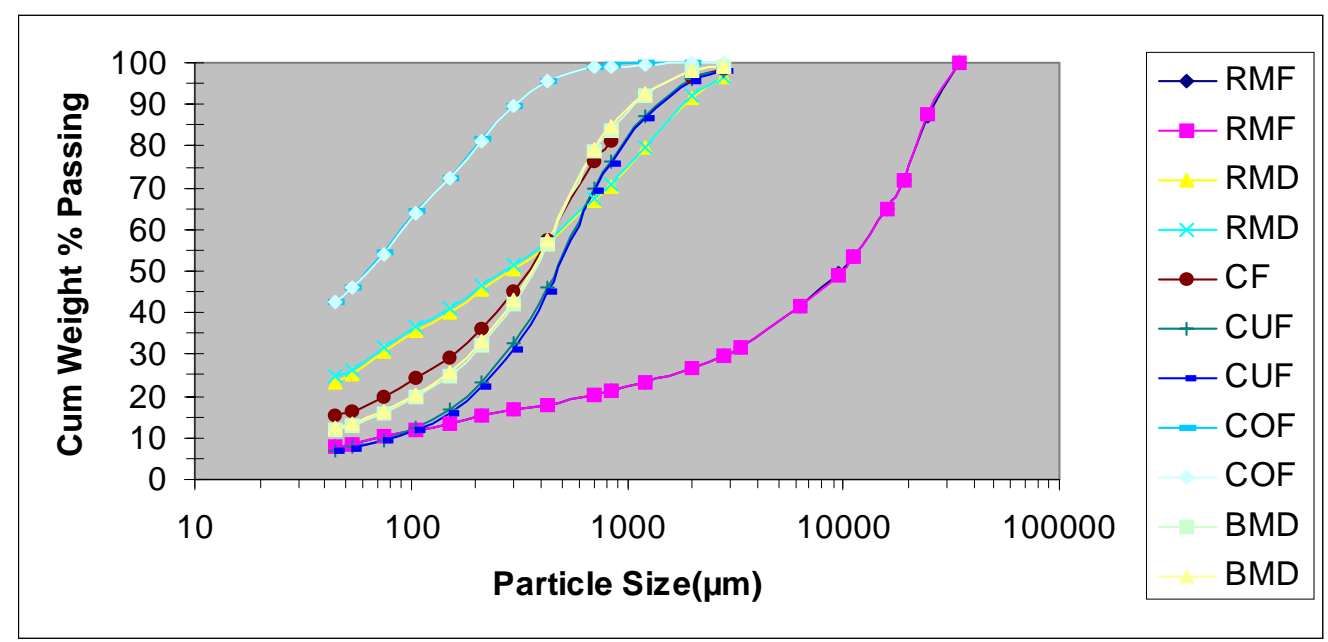

Figure 4: Experimental and Balanced Data for unit number 7 ( Nkana Concentrator)

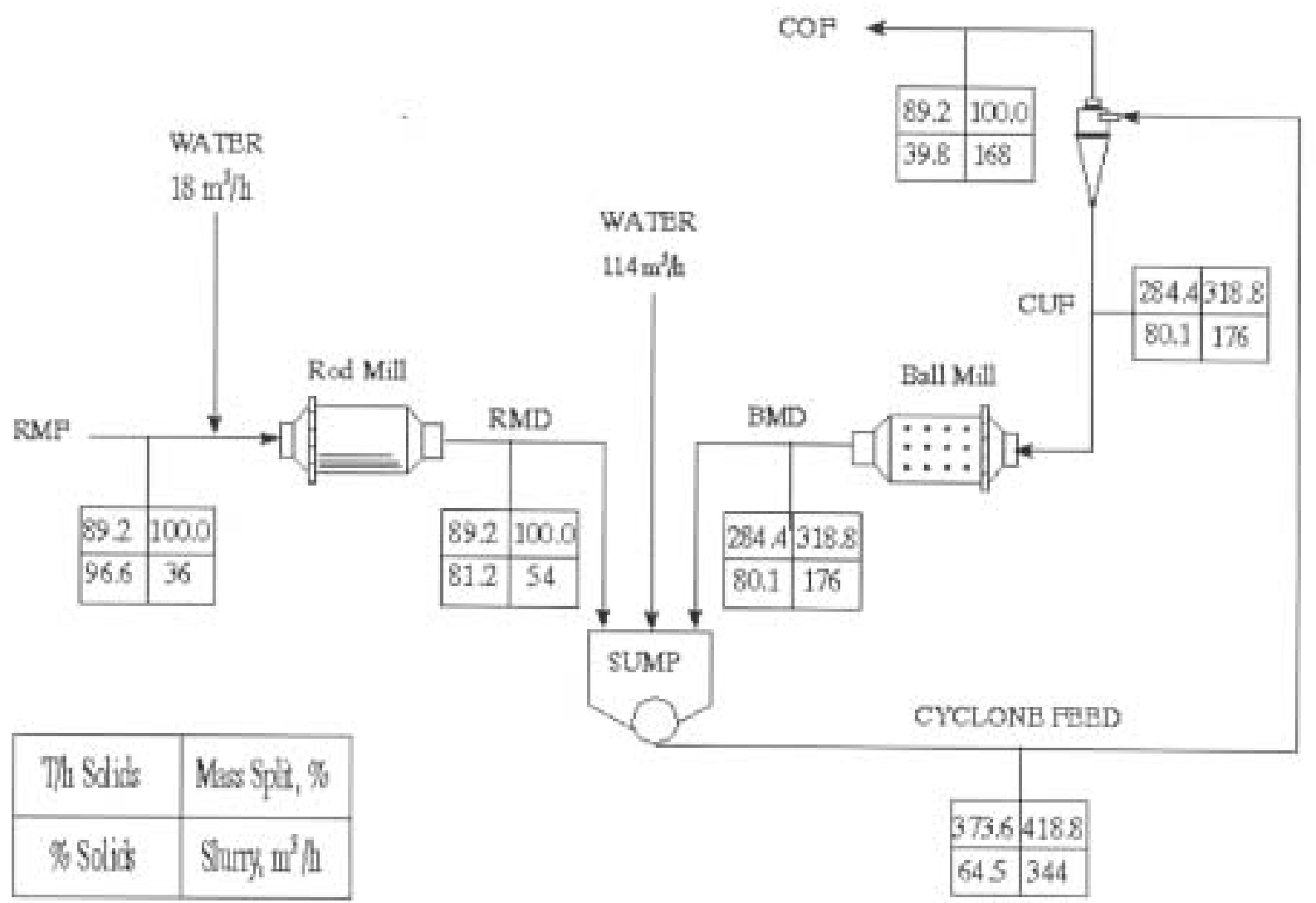

Figure 5: Simplified balanced Milling circuit number 7 of Nkana Mine Concentrator 


\section{CONCLUSION}

The use of well designed samplers and appropriate sampling techniques for cutting samples from the process streams in the milling plant has been proved to be a reliable procedure.

The use of JKSimMet software to carry out Mass balancing has been seen as a very powerful tool. The designed samplers can be used to cut representative samples from which reliable information for modelling milling circuits can be obtained. To achieve this, useful parameters such as internal diameter and length, speed, discharge grate holes, \% grate open area, Rod and Ball loads, Rod and Ball top size, total load filling and power drawn by the Mills must be established. The internal diameter and length of the cylindrical part, inlet diameter, vortex finder diameter, Spigot apex diameter cone angle of the hydrocyclone are also important parameters in the modelling of milling circuits. plant.

\section{REFFERENCE}

1. R.Smith \& G.V.James, The sampling of Bulk Materials [1981]

2. S.K.Jain, Ore Processing [1987].

3. Pierre M.Gy, Sampling of Particulate Materials. Theory and Practice [1982].

4. K.I.Afewu \& G.O. Lewis, Sampling of run-of-mine Mill feed - A practical approach . Journal of the South African Institute of Mining and Metallurgy October 1998. 